\title{
ColeçÕES, TRADUÇÕES E INTELECTUAIS: OliVEIRA VIANNA E O INTERCÂMBIO CULTURAL ENTRE ESCRITORES BRASILEIROS E ARGENTINOS NAS DÉCADAS DE 1930 E 1940
}

\author{
COLLECTIONS, TRANSLATIONS AND INTELLECTUALS: OLIVEIRA VIANNA AND THE CULTURAL \\ INTERCHANGE AMONG BRAZILIAN AND ARGENTINE WRITERS FROM 1930 AND 1940’S DECADE \\ Leonardo Seabra Coelho* \\ george.coelho@hotmail.com
}

RESUMO: Esse artigo discutirá a organização de parte da "sociedade de indivíduos" reunida em torno da ABL nas décadas de 1930 e 1940 e o intercâmbio cultural entre escritores brasileiros e argentinos nesses anos. Para analisar esse intercâmbio, lançaremos mão da versão em espanhol do livro Evolução do povo brasileiro, de Oliveira Vianna, publicada pelo governo argentino em 1937. Também discutiremos as nuances da criação da "Coleção Brasileira de Autores Argentinos" e da "Biblioteca de Autores Brasileños" e como essas coleções possibilitaram a aproximação entre intelectuais dos dois países. Nesse sentido, apresentaremos ao leitor como se estabeleceram as tentativas de aproximações entre escritores brasileiros ligados à $A B L$ - especificamente Oliveira Vianna - e parte da intelectualidade argentina; daí nossa tentativa de mapear parte da "sociedade de indivíduos" que compôs o campo literário desses dois países.

PALAVRAS-CHAVE: Literatura, Intelectuais, Intercâmbio.

ABSTRACT: This article is going to discuss part of the organization from "society of individuals" gathered around ABL from 1930 and 1940's decade and the cultural interchange among Brazilian and Argentine writers from these decades. To investigate this interchanging, we are going to leave the spanish version of Brazilian People Evolution aside, written by Oliveira Vianna, and published by the govern of Argentina in 1937. We are also going to discuss the nuances of the creation of "Brazilian Collection of Argentine writers" and "Library of Brasileños Authors" and how these collections made it possible to approximate these intellectuals from these countries. This way, we will present the reader how the attempt approximation among these intellectuals linked to $A B L$ has happened meanly Oliveira Vianna - and also demonstrate the argentine intellectuality; that's our attempt to map part of "society of individuals" which arranged the literature field from these countries.

KEYWORDS: Literature, Intellectuals, Interchanging.

\section{Introdução}

O presente artigo discutirá o intercâmbio cultural entre intelectuais brasileiros e argentinos nas décadas de 1930 e 1940. Para analisar esse intercâmbio, lançaremos mão da versão em espanhol do livro Evolução do povo brasileiro, de Oliveira Vianna, publicada pelo governo argentino em 1937. Além de possibilitar a aproximação das nuances que giram em torno do intercâmbio entre os escritores dos dois países, a análise dessa versão também

*Doutorado em História pela Universidade Federal de Goiás (2015). Atualmente é Professor Adjunto na Universidade Federal do Tocantins no curso de Licenciatura em Educação do Campo. 
abre espaço para reconstruir a história particular dessa obra e levantar proposições bastante interessantes sobre a relação entre Oliveira Vianna e a Casa de Machado de Assis.

No que concerne às fontes utilizadas neste estudo, compartilhamos da posição do historiador francês Marc Bloch (2002), ou seja, também julgamos importante considerar fontes numerosas e variadas para estudar os acontecimentos que se desenrolam no tempo. Assim, além da obra supracitada - preservada na coleção ${ }^{1}$ "Oliveira Vianna" e pertencente à Biblioteca Lúcio de Mendonça -, outras fontes históricas serão analisadas neste trabalho, entre elas: os documentos reunidos na pasta desse intelectual no Arquivo Múcio Leão ${ }^{2}$ da Academia Brasileira de Letras ( $A B L)$, as atas das sessões realizadas nos salões do Petit Trianon e os anais acadêmicos encontrados na Revista da Academia Brasileira de Letras. ${ }^{3}$ Ao ter por base essa premissa, os documentos utilizados neste artigo não serão tratados como fontes inoculadas e que por si só dizem a verdade, mas, como afirma o historiador francês, serão entendidos como vestígios do passado, que devem ser inquiridos para oferecer informações que não tencionam fornecer.

Acreditamos que, por meio do cruzamento dessas fontes históricas, poderemos reconstruir parte da "sociedade de indivíduos" reunida em torno da ABL nas décadas de 1930 e 1940. Apropriando-nos do conceito de Norbert Elias (1994), a noção de "sociedade de indivíduos" sugere uma questão central neste trabalho: o estudo da relação entre a pluralidade de pessoas e a pessoa singular, assim como abre espaço para entender a pessoa singular como pluralidade. Seguindo esse raciocínio, levaremos em conta a relação entre um indivíduo singular - Oliveira Vianna - e a pluralidade de pessoas envolvidas com as edições dos livros de Oliveira Vianna - escritores membros da $A B L$ e argentinos - e o projeto da tradução da obra desse intelectual para o espanhol. De modo geral, essa concepção nos possibilitará entender como os sujeitos individuais ligavam-se uns aos outros numa pluralidade e, concomitantemente, a sua situação dentro da sociedade, tendo por base o que o sociólogo alemão chama de habitus social.

\footnotetext{
${ }^{1} \mathrm{Na}$ coleção da Biblioteca Lúcio de Mendonça são encontrados 29 volumes de obras de autoria de Oliveira Vianna.

2 Três conjuntos documentais compõem esse arquivo: a documentação pessoal (cartas, bilhetes e telegramas), a documentação administrativa dos membros da Instituição e diversos recortes de jornais.

${ }^{3}$ Essa revista foi impressa pela Gráfica Bedeshi, entre 1937 e 1945, pela Gráfica Tupy, entre 1946 e 1948, e pela Companhia Brasileira de Artes Gráficas, entre 1949 e 1952. Os diretores da revista no período analisado foram: Adelmar Tavares, de 1937 a 1940, e, depois, em 1944; Afonso de Taunay, de 1941 a 1943; e Viriato Correia, entre 1945 e 1952.
} 
Para reconstruirmos parte da "sociedade de indivíduos" reunida em torno da ABL, optamos por dividir este artigo da seguinte forma: em um primeiro momento, daremos atenção às diversas edições do livro Evolução do povo brasileiro (1923), de Oliveira Vianna. Nessa reconstrução da história do livro, avaliamos que sua tradução para o espanhol e sua oferta para a $A B L$ - com dedicatória do autor - tornam-se parte importante dessa trajetória. $\mathrm{E}$, em um segundo momento, discutiremos como essa tradução para o espanhol refletiu a tentativa de intercâmbio cultural entre escritores dos dois países e, mais precisamente, entre Oliveira Vianna e a intelectualidade argentina. Por meio do conjunto documental analisado e da forma como estruturamos este texto, apresentaremos ao leitor como se estabeleceram as tentativas de aproximações entre escritores brasileiros ligados à $A B L$ especificamente Oliveira Vianna - e parte da intelectualidade argentina; daí nossa tentativa de mapear parte da "sociedade de indivíduos" que compôs o campo literário desses dois países.

\section{Escrita e reedições da Evolução do povo brasileiro}

Antes de nos atermos às problemáticas que envolvem os intercâmbios culturais entre escritores brasileiros e argentinos por meio da publicação da Evolução do povo brasileiro, é importante darmos atenção a algumas questões que envolvem as edições dessa obra no Brasil.

O livro Evolução do povo brasileiro foi publicado pela primeira vez em 1923 pela Editora Monteiro Lobato CO. Na época, Oliveira Vianna participava da equipe da Diretoria Geral de Estatística (DGE) responsável pela organização do primeiro Censo demográfico, realizado em 1920. De acordo com Vasconcelos Torres (1956), um dos mais renomados biógrafos de Oliveira Vianna, a indicação de Vianna a essa função derivava-se de seus conhecimentos históricos e sociais revelados no livro Populações meridionais do Brasil, publicado em 1920.

Os resultados obtidos com sua colaboração na DGE foram reunidos pelo intelectual no capítulo "O povo brasileiro e sua evolução" inserido no primeiro volume do Recenseamento do Brasil publicado pela Diretoria em 1922. Somente no ano seguinte Oliveira Vianna publicaria os resultados obtidos no Censo no livro Evolução do povo brasileiro. 
A obra foi apresentada ao público com a seguinte epígrafe de Georges Vacher de Lapouge: "La science politique est la science de l'évolution sociale, et l'art politique celui de diriger au mieux l'évolution à venir" (LAPOUGE apud VIANNA, 1923, p. 5). ${ }^{4}$ Ao inserir a frase desse eugenista e representante da antropossociologia ligada à escola francesa, Oliveira Vianna demonstra claramente sua simpatia à teoria racista de Arthur de Gabineau. Mesmo que o autor da epígrafe fosse filiado ao socialismo e às correntes anticlericais - posições bastante contrárias às do próprio Oliveira Vianna -, a citação dele está no livro. Essa é, aliás, uma das particularidades do pensamento vianniano: mesmo que as posições pessoais do teórico citado em sua pesquisa não se coadunassem com a dele próprio, o intelectual saquaremense não se intimidava em se apropriar de parte de seu pensamento para defender suas posições. No uso prático das posições teóricas de outros intelectuais, o escritor brasileiro deposita sua fé - como dito na epígrafe - na ciência aplicada à política como um dos caminhos que promoverá o desenvolvimento futuro das sociedades e, mais especificamente, promoverá o desenvolvimento futuro da sociedade brasileira.

Ao destacar o papel desempenhado por Oliveira Vianna no campo dos estudos sociológicos na primeira metade do século XX, Giselle M. Venancio (2001) avalia que a obra Evolução do povo brasileiro sintetizou parte das posições do autor expostas na obra anterior: Populações meridionais do Brasil (1920). Essas posições, segundo Venancio, pautavam-se pelo naturalismo sociológico como referencial teórico interpretativo da sociedade brasileira. Partindo dessa posição teórica, principalmente a sistematizada por Arthur de Gabineau, Oliveira Vianna procurou explicar a evolução do povo brasileiro pelos parâmetros dos determinismos mesológicos - geografia e clima - e biológicos - os grupos étnicos e a miscigenação. Segundo o autor, a influência recíproca desses dois fatores (meio e raça) teria gerado as características específicas do povo brasileiro.

Além de apropriar-se do naturalismo sociológico, esse intelectual também interpretou o processo de formação histórica do Brasil com base na ocupação do território. Para ele, esse processo deu-se de diversas formas: pela dispersão da nobreza colonial pelo interior rural; pela penetração dos sertões em busca dos indígenas; pela expansão pastoril nos planaltos; e, por fim, pela conquista das minas. Segundo Maria S. Bresciani (2007), esse

\footnotetext{
4 “A ciência política é a ciência da mudança social, e a arte política é a que leva a melhores desenvolvimentos futuros" (Tradução nossa).
} 
movimento em direção às terras do interior atuou, para Oliveira Vianna, como fator formador de homens cujos espíritos mantinham a existência da distinção e da importância hierárquica. Por meio da interpretação do processo de ocupação territorial, esse intelectual também faz reflexões sobre as variações dos tipos regionais. Essa preocupação o levou a definir os três principais grupos sociais: os paulistas, os mineiros e os fluminenses. Posteriormente, um quarto tipo ganharia destaque em suas obras: o vaqueiro do extremo Sul.

Antes do desenvolvimento do tema abordado no livro Evolução do povo brasileiro, Oliveira Vianna elabora uma introdução, dividida em duas justificativas que explicam a importância da obra: "O moderno conceito de evolução social" e a "Utilidade dos estudos brasileiros". Para estruturar o assunto tratado no livro, Oliveira Vianna dividiu seu estudo em três partes: "Evolução da sociedade", "Evolução da raça" e "Evolução das instituições políticas". Além dessa estrutura, encontramos diversas gravuras de Johann M. Rugendas, fotografias captando as produções agrícolas das diversas regiões pesquisadas no Censo, bem como mapas do território brasileiro entre os séculos XVI e XX.

A segunda edição da Evolução do povo brasileiro somente viria a público dez anos depois, em 1933, pela Companhia Editora Nacional para a "Biblioteca Pedagógica Brasileira", que compõe a Coleção Brasiliana, Série 5. $\underline{\text { a }}$, volume X. Essa coleção foi criada e dirigida por Fernando de Azevedo entre 1931 e 1946, sendo a série dedicada a publicar obras de escritores consagrados na busca de explicar a sociedade brasileira em textos ensaísticos de cunho histórico e sociológico. Sendo Oliveira Vianna um intelectual que tinha muita autoridade nas décadas de 1930, diversas outras obras suas foram publicadas por essa Coleção: Raça e assimilação (1932), Idealismo da Constituição (1939), Pequenos estudos de psicologia social (1942) e Populações meridionais do Brasil (1933/1938).

A terceira edição da Evolução do povo brasileiro foi publicada pela mesma Coleção, em 1938, e, assim como a edição anterior, teve um mapa do Brasil ilustrando sua capa. 


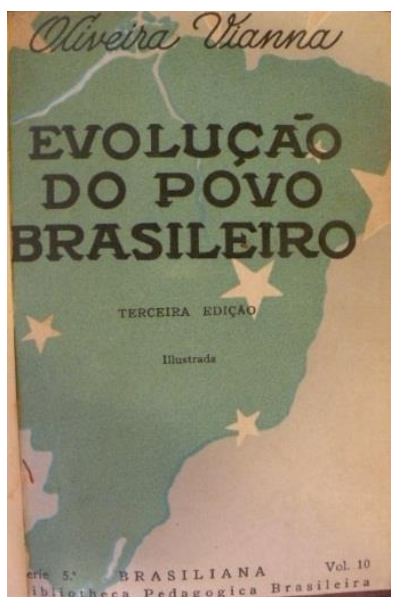

Figura 1 - Capa da terceira edição do livro Evolução do povo brasileiro (1938).

O recurso imagético do mapa do Brasil utilizado nas capas era comum nas publicações da coleção "Biblioteca Pedagógica Brasileira”. É claro que, além de estético, seu objetivo era reforçar o elo nacionalista entre a coleção, o autor e a obra. Contudo, além dos vínculos com o nacionalismo, essa também foi uma opção do editor, que, preocupado com uma apresentação homogênea das publicações, poderia consolidar, com isso, um perfil mais sólido entre as diversas obras de vários autores que tiveram obras publicadas pela série. De certo modo, esse recurso garantia uma uniformidade, o que fazia com que todas as obras fossem apresentadas como pertencentes a um único conjunto de publicações.

Pelas leituras das atas das reuniões da $A B L$, confirmamos que essa coleção era bastante apreciada pelos membros da Academia, visto que, além de Oliveira Vianna, diversos acadêmicos e futuros membros da Casa de Machado de Assis tiveram suas obras publicadas pela Coleção Brasiliana, entre eles: Gustavo Barroso, Pedro Calmon, Hélio Lobo, Roberto Simonsen, Cassiano Ricardo, Menotti del Picchia e Guilherme de Almeida. Entre os diversos elogios ao empreendimento iniciado por Fernando de Azevedo - eleito para a ABL em 1967 -, Afrânio Peixoto, em sessão acadêmica, destaca que essa coleção recebeu um "nome feliz" por ser "uma obra cultural sem precedentes" no campo das letras e do patriotismo, uma vez que "ensina, pela terra e pela gente [o brasileiro], a conhecer e amar e admirar o Brasil" (ABL, 1937, v. 54, p. 275).

A quarta edição (póstuma) da Evolução do povo brasileiro veio a público pela Livraria José Olympio Editora em 1956, quase vinte anos depois de lançada a terceira edição. A quarta edição fez parte do projeto da Livraria José Olympio Editora de publicar não apenas 
as obras já editadas de Oliveira Vianna, como também as inéditas, tudo ainda na década de 1950. A edição especial do jornal Letras Fluminense em razão do falecimento de Oliveira Vianna, em 1951, nos traz informações importantes sobre a relação entre o intelectual e a editora. Nesse jornal, o editor José Olympio afirma que Oliveira Vianna "alguns meses antes de falecer fez [...] um contrato, no qual ficou expressa a sua vontade de sermos nós os preservadores de sua obra literária e científica" (LETRAS FLUMINENSES, 1951, mar.-jun., ano 2, n. 6, p. 4). Na reportagem consta a lista de todas as obras de Oliveira Vianna que "achamse esgotadas" e as inéditas que seriam publicadas. Em 1959, o Jornal do Comércio de 5 de abril informa sobre as publicações das obras inéditas de Oliveira Vianna pela Livraria José Olympio Editora e cita seus títulos: História social da economia capitalista no Brasil, Ensaios, Antropossociologia das elites e Seleções telúricas. No entanto, dessa lista, nenhuma foi publicada pela editora; a primeira veio a público pela Editora da Universidade Federal Fluminense, em 1987; a segunda, pela Editora da Unicamp, em 1991; e as duas últimas permanecem inéditas. A não publicação dessas obras pode derivar do desinteresse comercial ou da falta de um acabamento melhor dado pelo autor às suas obras, mas o que fica é o cancelamento dessas publicações por parte da Livraria José Olympio Editora.

Uma questão interessante na relação entre Oliveira Vianna e essa editora está no fato de não ter havido mais publicações do livro Evolução do povo brasileiro, após a edição de 1956, e, como muitas outras obras desse intelectual - utilizando a expressão de Alberto Venâncio Filho -, essa também foi lançada ao "anonimato" por causa da "maldição do título". Quando se recorre a um retrospecto das publicações de Oliveira Vianna após os anos de 1970, percebe-se que apenas os livros o ocaso do Império, Instituições políticas brasileiras e Populações meridionais do Brasil foram obras editadas ainda em vida e que tiveram reedições após esse período.

Outra explicação pelo desinteresse pelas reedições das obras de Oliveira Vianna após os anos 1950 pode ser suscitada pela aproximação do autor com o regime ditatorial do Estado Novo. É comum pensar que essa associação consolidou o rótulo de "autor maldito" e, por isso, Vianna tenha sido relegado ao ostracismo por boa parte da intelectualidade nacional. Uma terceira explicação para o desinteresse pelas publicações da produção literária de Oliveira Vianna está no fato de que as Universidades, a partir da década de 1950, desprivilegiaram a produção sociológica e histórica marcada pelo viés ensaístico. Revela-se, 
assim, que, da mesma forma como ocorre o grande interesse nas publicações de suas obras até a década de 1950, há um crescente desinteresse pela publicação de seus livros nas décadas seguintes.

Ao percorrer os caminhos de apresentação da obra do intelectual saquaremense na $A B L$ e o papel dos editores na organização das edições, vemos a tentativa de valorização da capacidade intelectual de Oliveira Vianna. No afã de reforçar esse capital simbólico, a terceira edição de Evolução do povo brasileiro, de 1938, traz na contracapa a lista de todas as associações científicas a que o intelectual pertencia. A transcrição dessa lista reforça, para o leitor, as qualidades e o reconhecimento do escritor em diversas instituições científicas nacionais, latino-americanas e europeias. Vejamos:

Membro titular do Instituto Internacional de Antropologia; sócio da Sociedade dos Americanistas; da Sociedade Portuguesa de Antropologia e Etnografia e da Academia Portuguesa de História; da Union Cultural Universal, de Sevilha; da Academia de Ciências Sociais, de Havana; sócio efetivo do Instituto Histórico e Geográfico Brasileiro etc. (VIANNA, 1938, contracapa).

Naturalmente, como ainda não havia tomado posse na $A B L$ - foi eleito em maio de 1937 e tomou posse em julho de 1940 -, não consta nessa edição a informação de que Oliveira Vianna pertencia à Academia. Sabemos que, para a inclusão da informação que o autor era um integrante dessa Instituição, é necessária a aprovação da mesa Diretora da $A B L$, conforme o Art. 6. do Estatuto interno da Instituição: "Sem vênia da Academia, nenhum acadêmico tem o direito de declarar essa qualidade nos livros que publicar" ( $A B L$, 1940, Grifo nosso). O interessante é que, em todas as publicações feitas após sua posse em 1940, a longa lista de associações de que o autor é membro foi excluída e apenas a filiação do autor com a ABL é registrada. Frente a essa observação, poderíamos cogitar que as outras filiações do autor seriam suplantadas pelo prestígio da ABL? Sendo o perfil da Livraria José Olympio Editora e o da Coleção Brasiliana bastante ligados à intelectualidade oficial reunida em torno da $A B L$, acreditamos que sim, uma vez que a Academia era considerada um espaço privilegiado da intelectualidade brasileira.

Outra observação registrada durante a análise das reedições de livros de Oliveira Vianna é que o texto original sofreu diversas intervenções. Muitas reedições de livros desse intelectual contam com acréscimo de novos textos e prefácios; por exemplo, a edição de 1933 e de 1938 da Evolução do povo brasileiro contam com novos prefácios. 
A inserção de novos textos - para nós, o prefácio é um novo texto - em suas obras reeditadas tem importância particular, pois, sabe-se, o intelectual saquaremense não costumava alterar suas obras. Essa afirmativa é corroborada no prefácio da edição de 1933 de Evolução do povo brasileiro. Logo no primeiro parágrafo desse prefácio, o intelectual afirma que

este livro sai nesta edição como saiu na primeira edição: não lhe introduzi modificação alguma, salvo ligeiríssimo retoque de forma.

Não vi razão para alterá-lo nem no seu pensamento, nem nas suas conclusões. Estes dez anos, decorridos depois da sua primeira edição, não trouxeram nenhum desmentido às suas afirmações; antes, as robusteceram em muitos pontos [...]

Revendo-as, agora, reconheço que o meu pensamento não sofreu [...] modificação alguma. Daí subscrevê-las, hoje, como o fiz há dez anos (VIANNA, 1933, p. 1).

Na terceira edição dessa obra - portanto em 1938 -, Oliveira Vianna escreve um novo prefácio, em que novamente justifica a atualidade de suas teses e o motivo de não alterá-las. Para o intelectual:

Este livro foi escrito em 1922 [...]. Neste decurso de tempo, o Brasil mudou muito na sua estrutura: tem crescido, evoluído, progredido. No entanto, repito nesta nova edição o que já disse no prefácio da anterior: não há motivo novo que me leve a modificar qualquer das conclusões a que cheguei (VIANNA, 1938, p. 13-18).

Na quarta edição de Populações meridionais do Brasil, publicada em 1938, Oliveira Vianna também reforça sua posição de não alterar o conteúdo de seus livros:

Este livro sai nesta quarta edição tal como na primeira. Não lhe modifiquei nada: não costumo alterar ou retificar o conteúdo de livros, que público. Os erros, que porventura contenham, que os corrija a crítica dos competentes; ou o próprio autor, em novos livros. É de Durkheim o conceito de que - Un livre a une individualité qu'il doit garder. II convient de lui laisser la physionomie sous laquelle il s'est fait connaître ${ }^{5}$ (VIANNA, 1938, p. I).

Como podemos ver nos fragmentos transcritos desses prefácios, Oliveira Vianna é incisivo ao afirmar que não é de seu costume alterar suas ideias nas reedições de obras. Apesar do reconhecimento das modificações sociais e políticas pelas quais o Brasil passara entre 1922 e 1938, o autor prefere escrever outras obras para reformular suas posições ou deixar os "possíveis erros" para análise dos "críticos competentes", visto que, para ele, a obra deve manter seu formato original. As modificações empreendidas no texto, segundo o

\footnotetext{
5 "Um livro tem uma individualidade que deve ser mantida. Convém manter-lhe a aparência com que se tornou conhecido" (Tradução nossa).
} 
intelectual, têm apenas a preocupação em melhorar a forma e deixar seu texto mais compreensível para o leitor.

O fato de Oliveira Vianna ter justificado a prática de não alterar o conteúdo de suas obras nos faz pensar que a inclusão de novos prefácios nas reedições merece uma atenção mais específica por parte das análises históricas. Dessa constatação, podemos sugerir algumas questões: Será que, ao acrescentar textos novos, o autor não modificaria o conteúdo de sua obra? Para Oliveira Vianna, a inserção de prefácios não era entendida como alteração nas obras? Até que ponto as mudanças na forma não interferiram no sentido inicial do texto? Essas indagações, apesar de pertinentes, devem ser respondidas em futuras análises, uma vez que nosso objetivo neste artigo é analisar o intercâmbio cultural entre escritores brasileiros e argentinos. Dito isso, vejamos agora como a tradução da Evolução do povo brasileiro para o espanhol pode refletir a aproximação entre a intelectualidade dos dois países e reconstruir parte da "sociedade de indivíduos" reunidos em torno da ABL.

\section{A obra Evolução do povo brasileiro e o intercâmbio latino-americano}

O jornal Gazeta de Notícias ${ }^{6}$ de 23 de dezembro de 1937, editado na cidade do Rio de Janeiro, informa que o livro Evolução do povo brasileiro, de Oliveira Vianna, foi traduzido para o espanhol por Júlio E. Payro. Essa obra, juntamente com outras publicações de autores brasileiros, irá compor a coleção "Biblioteca de Autores Brasileños", organizada em 1937 pela Junta de História e Numismática Americana sediada em Buenos Aires. Essa coleção ficou sob direção do Ministro de Estado argentino Miguel Â. Carcano ${ }^{7}$, filho do embaixador Ramón J. Carcano ${ }^{8}$. O Gazeta de Notícias exalta a criação da "Biblioteca de Autores Brasileños" como mais um resultado "da intensa obra de intercâmbio cultural que vem sendo desenvolvida entre os dois países" (Arquivo pessoal Oliveira Vianna ABL, Pasta 356-B41).

Antes mesmo de se tornarem sócios correspondentes da $A B L$, as duas personalidades argentinas citadas anteriormente haviam sido homenageadas diversas vezes em sessões

\footnotetext{
${ }^{6}$ Todas as citações referentes a fontes de jornais e cartas feitas neste artigo foram encontradas na pasta Oliveira Vianna no Arquivo Múcio Leão na ABL.

${ }^{7}$ Miguel Ângelo Carcano tornou-se sócio correspondente da ABL em 1959 para a 5. a posição da cadeira de $n$. 15.

${ }^{8}$ Ramón J. Cárcano tornou-se sócio correspondente da ABL em 1938 para a 3. a posição da cadeira de n. 19.
} 
públicas na Casa de Machado de Assis, principalmente por suas ações no fortalecimento das relações entre os escritores das duas nações.

No que concerne ao intercâmbio cultural entre Brasil e Argentina, Getúlio Vargas no cargo de Chefe do Governo Provisório - procurou diversas vezes estabelecer a aproximação entre os dois países. Entre essas tentativas, podemos citar o Decreto n. 24.394, de 13 de junho de 1934. Esse decreto, homologado em razão da visita do Presidente da Argentina - o então General Augustin P. Justo - ao Brasil, ratificava o intercâmbio cultural entre os dois países. Logo no Art. 1. conhecemos o objetivo desse acordo:

As instituições ou associações científicas culturais literárias e artísticas do
Brasil e da Argentina procurarão fomentar por todos os meios o
intercâmbio intelectual entre brasileiros e argentinos, propiciando as
viagens de seus membros e de professores das Universidades e
estabelecimentos de ensino superior de um país ao outro, a fim de
professarem cursos de suas especialidades ou dizerem conferências a
respeito de coisas brasileiras e argentinas (BRASIL, 1934).

Além do convênio oficial que firmava a viagem de intelectuais e professores às universidades dos dois países, vemos que as tentativas de aproximação estabelecidas pela ABL extrapolavam aquelas encabeçadas pelas esferas governamentais. Nas atas e resumos das sessões da $A B L$, encontramos diversas notícias de viagem de acadêmicos da Casa de Machado de Assis ao país vizinho, assim como a recepção de intelectuais argentinos nos salões do Petit Trianon. Além das visitas que pretendiam cumprir o decreto presidencial, a criação da "Coleção de Autores Brasileños" pelo governo Argentino foi uma tentativa prática de consolidação desse intercâmbio, até porque seus idealizadores - um ministro de Estado e um embaixador - estavam intrinsecamente ligados ao governo daquele país.

A coleção argentina teve como primeiro volume o livro História da Civilização Brasileira, de Pedro Calmon. Após a tradução das obras de Pedro Calmon e Oliveira Vianna, Afrânio Peixoto - presidente da ABL em 1937 -, em sessão acadêmica, nos informa que as próximas traduções seriam El Emperador D. Pedro II, de Afonso Celso, e Los Sertones, de Euclides da Cunha, ambas para 1938. Além das traduções anunciadas, também foram publicadas pela referida coleção as seguintes obras: Conferencias y discursos, de Rui Barbosa, em 1939; Mis memorias de los otros, de Rodrigo Octávio, em 1940; Casa-grande \& senzala, de Gilberto Freyre, em 1942; Pequeña historia de la literatura brasileña, de Ronald de Carvalho, em 1943; San Pablo en siglo XVI, de Afonso de Taunay, em 1947; e La vida en la selva, de Candido de Melo Leitão, em 1949. 
É possível perceber que os únicos autores não acadêmicos traduzidos são Gilberto Freyre, Ronald de Carvalho e Candido de Melo Leitão. A tradução do primeiro autor justificase por ser uma obra clássica de um dos principais referenciais da sociologia brasileira da década de 1930. O segundo autor teve sua obra inserida na coleção por ser um grande crítico literário e vencedor de diversos prêmios concedidos pela ABL. O terceiro autor não acadêmico com obra traduzida para a coleção argentina é considerado o pai dos estudos sobre aracnologia na América do Sul, um dos maiores estudiosos da biogeografia no Brasil e Presidente da Academia Brasileira de ciências entre 1943 e 1945.

Com essa lista de traduções, fica claro o perfil dos autores com obras publicadas por essa coleção: membros da $A B L$ ou autores de grande aceitação entre a intelectualidade brasileira. A tradução da obra de Oliveira Vianna cumpria essas duas condições, visto que foi eleito para a cadeira de n. 8 da ABL em 1937 e era um dos mais renomados escritores brasileiros no campo da sociologia.

Em retribuição à iniciativa argentina, criou-se no Brasil, em 1938, a "Coleção Brasileira de Autores Argentinos", organizada e dirigida pelo Serviço de Cooperação Internacional do Ministério das Relações Exteriores, sob supervisão do Ministro Osvaldo Aranha e de Pedro Calmon. Nesse mesmo ano, Miguel Osório de Almeida - Presidente da $A B L$ em 1938 - ofereceu à Academia os dois primeiros volumes da coleção brasileira dedicada a autores argentinos: Síntese da História da Civilização Argentina (1938), de Ricardo Levene, e De Caseros ao XI de Setembro (1939), de Ramón J. Cárcano (eleito membro da Academia Argentina de Letras em 1938). Outras obras de autores argentinos também pertenceram a essa coleção, entre elas: Orações setectas (1940), de Bartolomé Mitre (eleito sócio correspondente da ABL em 1898); Bases e pontos de partida para a organização política da República Argentina (1941), de Juan Batista Albert; Vidas argentinas (1942), de Octávio R. Amadeo; O santo da espada (San Martir) (1948), de Ricardo Rojas (eleito sócio correspondente da ABL em 1943); Mitre: uma década de sua vida política (1950), de Rodolfo Rivarola (eleito sócio correspondente da ABL em 1935); e Recordação da província (1952), de Domingo Faustino Sarmiento.

A maioria das obras dos escritores argentinos que compõem a "Coleção Brasileira de Autores Argentinos" foi traduzida por J. Paulo de Medeiros e prefaciadas por Pedro Calmon, Álvaro Lins, Oswaldo Aranha, Afrânio de Melo Franco e Octávio Tarquinio de Souza. 
No caso das obras de autores brasileiros pertencentes à "Biblioteca de Autores Brasileños", a maior parte foi traduzida por Julio E. Payró e prefaciada por Emilio Ravignani, Ricardo Levene, Rômulo Zabala, Max Fleiuss, Mariano de Vedia, Ricardo Sáez-Hayes (eleito membro da Academia Argentina de Letras em 1948 e membro-correspondente da ABL em 1962), Octávio R. Amadeo e Rodolfo Rivarola.

Os índices de publicações dessas duas coleções nos relevam que elas eram formadas por um grupo bastante fechado, uma "sociedade de indivíduos" composta por membros das Academias de Letras, Ciência e História, sócios correspondentes de ambas instituições, professores universitários, políticos e diplomatas dos dois países.

Segundo Gustavo Sorá (2002), a "Biblioteca de Autores Brasileños" foi um projeto oficial do Ministério da Justiça e Instrução Pública coordenado por uma Comissão Revisora de Textos de História e Geografia da América sediada em Buenos Aires. O autor constata que sua homóloga no Brasil seria a "Coleção Brasiliana". Sendo assim, as duas coleções compõem um conjunto de medidas oficiais que reuniram ensaios dedicados às interpretações das realidades nacionais. Não discordamos que essas tentativas tenham sido frutos de medidas oficiais, mas não estamos de acordo com a opinião de que a "Coleção Brasiliana" era homóloga à coleção argentina, uma vez que a coleção dirigida por Fernando de Azevedo publicava preferencialmente autores brasileiros. Como homóloga no Brasil, apontamos a "Coleção Brasileira de Autores Argentinos", ou seja, essa coleção e a "Biblioteca de Autores Brasileños" tornavam-se uma via de mão dupla entre escritores dos dois países.

Além da via de mão dupla estabelecida entre as duas coleções, as atas e anais da $A B L$ revelam diversas homenagens às personalidades argentinas, ofertas de exemplares de obras e revistas literárias produzidas no país vizinho, pinturas e elogios às ações desenvolvidas por suas Academias de Letras e de História. Todas essas atitudes objetivavam reforçar o intercâmbio cultural entre os países latino-americanos, ou melhor, essas práticas se assentavam na tentativa de estreitar as distâncias culturais entre o Brasil e a Argentina. De modo geral, tais ações buscavam consolidar uma "sociedade de indivíduos", basicamente uma sociedade de escritores ligados a espaços institucionalizados de produção literária.

Paralelamente às homenagens, as eleições de personalidades argentinas como sócios correspondentes - nove argentinos foram eleitos entre 1898 e 1959 - e as 
conferências sobre a literatura pan-americana reunidas no volume Panorama da literatura estrangeira contemporânea (1943) completavam essas ações de aproximação. Além disso, diversos textos - entre 1937 e 1947 -, tratando da aproximação entre Brasil e Argentina, são publicados nos anais acadêmicos da $A B L$, conforme descreve o quadro abaixo:

\begin{tabular}{|l|l|c|}
\hline \multicolumn{1}{|c|}{ ACADÊMICOS } & \multicolumn{1}{|c|}{ TEXTOS } & ANO \\
\hline $\begin{array}{l}\text { Afonso de Taunay, Rodrigo Octávio, } \\
\text { Athaulfo de Paiva e Hélio Lobo }\end{array}$ & $\begin{array}{l}\text { Homenagem à República Argentina e ao } \\
\text { embaixador D. Ramon J. Carcano }\end{array}$ & 1937 \\
\hline D. Ramon L. Carcano & $\begin{array}{l}\text { Homenagem à República Argentina e ao } \\
\text { embaixador D. Ramón J. Carcano }\end{array}$ & 1937 \\
\hline Hélio Lobo & $\begin{array}{l}\text { A cooperação intelectual na conferência } \\
\text { da Paz de Buenos Aires }\end{array}$ & 1937 \\
\hline Hélio Lobo e Cláudio de Souza & $\begin{array}{l}\text { Homenagem ao embaixador José Maria } \\
\text { Cantilo }\end{array}$ & 1938 \\
\hline Celso Vieira & Brasil-Argentina & 1940 \\
\hline Henrique Larreta & Homenagem ao Sr. Enrique Larreta & 1941 \\
\hline João Neves da Fontoura e Leví Carneiro & Homenagem ao Sr. Enrique Larreta & 1941 \\
\hline Leví Carneiro e Pedro Calmon & Rodolfo Rivarola & 1942 \\
\hline Enrique Ruiz Guiñazú & $\begin{array}{l}\text { Homenagem aos delegados da terceira } \\
\text { reunião de consulta dos chanceleres } \\
\text { americanos }\end{array}$ & 1942 \\
\hline José Carlos de Macedo Soares & Na Academia Argentina de Letras & 1943 \\
\hline Bernardo A. Houssay & El hombre de ciencia & 1943 \\
\hline José Carlos de Macedo Soares & $\begin{array}{l}\text { O movimento político-militar na } \\
\text { Argentina }\end{array}$ & 1945 \\
\hline Henrique Larreta & $\begin{array}{l}\text { Hermano sol, hermana flor, hermana } \\
\text { agua }\end{array}$ & 1947 \\
\hline
\end{tabular}

Quadro 1 - Quadro elaborado com base nos índices dos anais acadêmicos entre os anos 1937 e 1947.

No intercâmbio estabelecido nos salões do Petit Trianon, entre 1937 e 1947, apenas as conferências de José Carlos de Macedo Soares e de Hélio Lobo destacam exclusivamente a atividade intelectual daquele país. As homenagens a José Maria Contilo não estão voltadas para sua condição de sócio correspondente, e sim para sua posição política, ou seja, a de embaixador. O quadro aponta também as conferências de D. Ramon L. Carcano e Henrique Larreta agradecendo as homenagens prestadas a eles; Larreta também envia um texto na forma de conto. Já Bernardo A. Houssay e Enrique Ruiz Guiñazú - os únicos que não são sócios correspondentes (o primeiro era um grande cientista e vencedor do Prêmio Nobel de Medicina em 1947 e o segundo, famoso político e diplomata) - enviam, respectivamente, uma crônica e um discurso em homenagem aos chanceleres americanos. Por fim, um segundo discurso de José Carlos de Macedo Soares, proferido em 1945, aborda estritamente a situação política do país vizinho e não questões literárias. 
Esses exemplos permitem constatar que, na medida do possível, os acadêmicos tentavam não trazer questões políticas para o seio da ABL. Vemos que o silêncio a respeito dessas questões não era possível, haja vista que encontramos homenagens ao indivíduo na condição de embaixador e comentários referentes ao "movimento político-militar na Argentina", denominado pela historiografia como "Revolução de 43". Esses indícios reforçam a opinião de Alessandra El Far (2000) e de João Paulo Rodrigues (2001) de que as fronteiras entre o campo político e o campo literário nem sempre encontram-se bem definidas nos salões da $A B L$, apesar da defesa da neutralidade em assuntos de cunho político demarcada desde o discurso fundador de Machado de Assis em 1897.

\section{A interação de Oliveira Vianna com os grupos da ABL}

Após descrevermos a história particular do livro Evolução do povo brasileiro, as problemáticas que giravam em torno da criação das duas coleções e o intercâmbio cultural estabelecido nos salões do Petit Trianon, vejamos, agora, como Oliveira Vianna interagia com esses grupos. Primeiramente, veremos as dinâmicas entre o intelectual saquaremense e a $A B L$ e, posteriormente, vínculos com intelectuais argentinos.

Na Biblioteca Lúcio de Mendonça, encontramos diversas obras de Oliveira Vianna com dedicatória para a $A B L$, entre elas a edição em espanhol de Evolução do povo brasileiro. A prática de oferecer obras com dedicatória para a Academia é um habitus comum entre os membros da $\mathrm{ABL}$ e, como podemos ver, Oliveira Vianna participava dessa prática. Poderíamos achar que parte dessas obras dedicadas para a Biblioteca Lúcio de Mendonça seria para cumprir o requisito do Regimento Interno, que exige a apresentação de produção literária; no entanto, vemos que, mesmo após sua eleição, Oliveira Vianna ainda oferecia seus livros com dedicatórias para a Instituição. Até mesmo após seu falecimento, em 1951, seus familiares continuam ofertando obras póstumas para a Biblioteca Lúcio de Mendonça.

O intelectual saquaremense mantém a atitude definida por Giselle M. Venancio (2015) como "presentes de papel". Essa autora demonstra que, por meio dessas dedicatórias, Oliveira Vianna mantinha uma rede de sociabilidade. Consideramos que a oferta de seus textos para a Academia revela o interesse do autor e de seus familiares em obter reconhecimento e reforçar a memória desse intelectual entre os membros da ABL. Frente a essa prática, concluímos que Oliveira Vianna não era avesso à Academia; pelo 
contrário: a oferta de exemplares com dedicatórias em seus livros demonstra o reconhecimento e a solidariedade para com essa instituição.

Tratando mais diretamente sobre o livro de Oliveira Vianna traduzido para o espanhol, Rodolfo Rivarola ${ }^{9}$, no prefácio dessa edição, nos dá uma pequena impressão da recepção desse intelectual entre os argentinos. No referido prefácio, escrito em junho de 1937, Rodolfo Rivarola explica por que essa obra de Oliveira Vianna mereceu entrar para a coleção argentina. Mesmo considerando que tenha sido escrita em pouco tempo e com um objetivo bastante prático - para a edição oficial do Censo de 1920 -, o escritor argentino afirma que essa obra tem o mérito devido a seu "labor cientifico, a su dedicación especial en penetrar en lo más recondito de la vida de su pueblo" (RIVAROLA, 1937, p. 9). Para reforçar sua análise científica sobre esse livro, o prefaciante lembra o conjunto da obra do intelectual brasileiro, assim como as novas publicações anunciadas em 1933.

Ao refletir filosoficamente sobre o termo "evolución" empregado pelo intelectual brasileiro, o prefaciante rebate as teorias evolucionista de Herbert Spencer, visto que o conceito de "evolución" empregado no livro de Oliveira Vianna não é "teoria, ni conjectura", mas derivado da "tierra" e do "hombre que la habita" (RIVAROLA, 1937, p. 12). Seguindo essa premissa, Rodolfo Rivarola chega à conclusão de que a formação da sociedade brasileira ainda não se encerrara, pois a "heterogeneidad inicial" vai em direção a "fusión de razas", a qual terá como consequência a "evolución de las instituiciones políticas" (RIVAROLA, 1937, p. 12/14).

Ao lado da concepção de "evolución" adotada por Oliveira Vianna, para Rodolfo Rivarola a interpretação do intelectual brasileiro sobre o papel do Império na organização da sociedade brasileira é o segundo mérito dessa obra. A interpretação vianniana é tida, pelo historiador argentino, como pano de fundo para pensar a realidade de seu país e as diferenças entre as duas nações. Para o escritor argentino, o modelo proposto por Oliveira Vianna possibilita entender a fragmentação da "unidad colonial" espanhola e, acima de tudo, a estruturação da "unidad nacional" argentina em contraposição à realidade brasileira.

\footnotetext{
${ }^{9}$ Rodolfo Rivarola era constantemente lembrado nas sessões realizadas no Petit Trianon, principalmente em razão de seu aniversário de 80 anos, em dezembro de 1937. Esse escritor argentino havia sido eleito em 1934 como $3 .^{\circ}$ ocupante da cadeira de $\mathrm{n}$. 15 de sócio correspondente e, em 1935, tornou-se presidente do Instituto Cultural Brasil-Argentina em Buenos Aires. Como forma de reforçar intercâmbios entre os dois países, a congênere desse Instituto no Brasil tinha sua sede no Rio de Janeiro sob presidência de Rodrigo Octávio, também membro da ABL.
} 
Em diversas oportunidades, Oliveira Vianna agradece publicamente pelo reconhecimento dado a ele pelos intelectuais argentinos. Na tradução de Evolução do povo brasileiro para o espanhol, podemos ler uma carta de Oliveira Vianna datada de 27 de julho de 1937 agradecendo ao historiador Ricardo Levene pela iniciativa de publicar sua obra e a de seu "colega y amigo Pedro Calmon". Outro exemplo pode ser dado ao lermos a ata da sessão de 14 de novembro de 1942, realizada nos salões do Petit Trianon. Nessa ocasião, Oliveira Vianna fala em homenagem à memória do sócio correspondente Rodolfo Rivarola, falecido em 10 de novembro de 1942. Nessa homenagem, o intelectual lembra do momento em que o conhecera para agradecê-lo pelas "palavras de tão alta generosidade com que prefaciou a edição em espanhol da Evolução do povo brasileiro" (ABL, 1942, v. 64, p. 334). Esses dois intelectuais argentinos estavam diretamente envolvidos na elaboração da "Biblioteca de Autores Brasileños" patrocinada pelo governo argentino e, principalmente, na publicação da obra de Oliveira Vianna: Levene como diretor da coleção e Rivarola como prefaciador desse volume. Por esse motivo, o intelectual saquaremense faz questão de deixar público o seu agradecimento.

Ao homenagear Monteiro Lobato por ocasião de seu falecimento em 1948, Oliveira Vianna lembra que foi o editor paulista que o aproximou de José Ingenieros. Esse escritor argentino tinha grande prestígio entre a intelectualidade sul-americana nas primeiras décadas do século $X X$, principalmente pelos estudos sociológicos que destacavam a identidade latino-americana. O jornal Letras Fluminense dedicado à Oliveira Vianna nos dá uma pista sobre essa aproximação, ainda que Vianna não o tenha conhecido pessoalmente em virtude do falecimento precoce do intelectual argentino em 1925. Ao reproduzir uma carta de José Ingenieros para Monteiro Lobato, esse jornal torna público o reconhecimento de Oliveira Vianna por parte de um escritor argentino. Nessa missiva, José Ingenieros comenta sobre o método, as ideias e a erudição de Oliveira Vianna, reconhecendo que Populações meridionais do Brasil é uma "de las obras más notables em su género que hasta ahora se há escrito em Sud américa", pois "se trata de um verdadeiro monumento que honra a la cultura de todo el continente" (LETRAS FLUMINENSES, 1951, mar.-jun., ano 2, n. 6, p. 11). Para Oliveira Vianna, a importância desse reconhecimento por parte do intelectual argentino se comprova pela inserção de fragmentos dessa carta como epígrafe na terceira edição de Populações meridionais do Brasil, publicada em 1933. 
Além das homenagens póstumas proferidas por Oliveira Vianna em memória de intelectuais argentinos e da inserção de fragmentos de cartas de escritores daquele país em suas obras, o Arquivo Múcio Leão da ABL preservou um recorte do Jornal do Comércio, de 20 de setembro de 1942, que reproduz uma carta do ex-embaixador argentino Octávio Amadeo - outra personalidade que teve sua obra inserida na "Coleção Brasileira de Autores Argentinos" - endereçada a Oliveira Vianna. Nessa correspondência, o ex-embaixador se solidariza com a agressão sofrida pelo Brasil por submarinos nazistas. Em resposta, Oliveira Vianna dirige-se ao político argentino como "amigo" que representa "os sentimentos da elite argentina" (Arquivo pessoal Oliveira Vianna ABL, Pasta 350-0-3). Nessa missiva, Oliveira Vianna tenta convencer o ex-embaixador argentino de que seu país também está no mesmo caminho e espera que cerre fileira ao lado do Brasil para defender a "soberania de cada nação americana" (Arquivo pessoal Oliveira Vianna ABL, Pasta 350-0-3). Ao finalizar a resposta a Octávio Amadeo, o intelectual brasileiro agradece a solidariedade, colocando-se como "brasileiro e americano", expressão que demonstra o espírito americanizador de Oliveira Vianna frente à ameaça nazista (Arquivo pessoal Oliveira Vianna ABL, Pasta 350-O$3)$.

A leitura da tradução de Evolução do povo brasileiro para o espanhol encontrada na coleção Oliveira Vianna da Biblioteca Lúcio de Mendonça, as tentativas de intercâmbio cultural entre Brasil e Argentina, as missivas entre Oliveira Vianna e escritores argentinos e a inserção de fragmentos dessas cartas em suas obras nos revelam a rede de relações estabelecida entre o intelectual saquaremense, a ABL e escritores latino-americanos. Esse é apenas um exemplo da riqueza de se trabalharem as coleções de obras de intelectuais em bibliotecas institucionais; elas servem como pontos de partida para rastrear as interações entre os escritores, além de poderem oferecer caminhos para rastrear as formas como se organizam determinada "sociedade de indivíduos".

\section{Considerações finais}

Além de traçar as aproximações entre Oliveira Vianna e os ritus dos acadêmicos no interior da $\mathrm{ABL}$ - os quais foram demonstrados pela oferta de obras com dedicatórias para a Biblioteca Lúcio de Mendonça e as homenagens em sessões públicas -, neste artigo também acompanhamos a reedição de seus livros. A partir da análise dessas reedições, percebemos a 
mudança nos prefácios e, acima de tudo, as formas como essas obras foram apresentadas ao leitor. A comparação entre elementos externos dos livros reeditados também ofereceu caminhos para se perceber a construção do livro como suporte cultural, seja na escolha da capa, seja na inclusão e exclusão da lista de filiação do autor ou no acréscimo de diferentes prefácios que tentam justificar a validade da obra em tempos diferentes.

No que se refere à edição e reedição de obras de Oliveira Vianna, é comum se discutir que esse intelectual, na década de 1920, ascendeu na esfera pública como um promissor escritor ligado à sociologia e história - ambas no campo ensaístico - voltadas para a análise da sociedade brasileira. Na década de 1930, o intelectual torna-se um expoente no campo burocrático do Estado vinculado à legislação trabalhista e um consagrado escritor, confirmado pela quantidade de obras reeditadas nessa década. Na primeira metade da década de 1940, torna-se um intelectual de grande porte, vinculado à $A B L$, juiz federal e autor de obras ligadas a questões jurídicas e institucionais do Estado brasileiro. Na década de 1950, mesmo após o falecimento do autor, a figura de Oliveira Vianna ainda ressoa os anos de glória de sua posição intelectual, ainda que a memória histórica o ligasse ao regime ditatorial estado-novista. Da década de 1960 em diante, o intelectual cai em desgraça como autor maldito, haja vista que a publicação de obras reeditadas ou inéditas ocorre de forma discreta e esporádica.

A nosso ver, tal esquecimento acontece por dois motivos: pela fragilidade científica de suas argumentações, uma vez que sua escrita era de caráter ensaístico, e pelo fato de as universidades tomarem o espaço autorizado institucionalmente como produtora do conhecimento científico sobre a sociedade brasileira. As interpretações dele sobre a importância da raça também caem em descrédito juntamente com a crítica sobre a teoria da "democracia racial" iniciada pela escola organizada em torno de Florestan Fernandes na Universidade de São Paulo (USP). Mesmo que na década de 1970 um novo regime ditatorial passasse a governar o Brasil, as teses de Oliveira Vianna sobre o estado corporativo e o sindicato tornam-se caducas frente à nova tecnocracia inaugurada pelo governo militar no pós-desenvolvimentismo dos anos de 1950.

Além de discutir a trajetória desse intelectual com base na reedição de suas obras, este artigo também procurou demonstrar que, em um período em que era considerado expoente no campo da sociologia brasileira, Oliveira Vianna teve sua obra traduzida para 
uma coleção que buscava o intercâmbio entre escritores brasileiros e argentinos. As notícias na imprensa sobre a tradução de Evolução do povo brasileiro para o espanhol, a menção dessa publicação em sessões acadêmicas na $A B L$ e a leitura do prefácio da versão em espanhol dessa obra levantaram pontos importantes sobre a "sociedade de escritores" articulados nesse projeto. Por um lado, demonstra o intercâmbio cultural estabelecido entre escritores ligados à $A B L$ e escritores argentinos por meio da "Biblioteca de Autores Brasileños" e a "Coleção Brasileira de Autores Argentinos". Por outro, apresenta o reconhecimento de Oliveira Vianna entre os membros da $A B L$, visto que, mesmo antes de tomar posse, uma de suas obras foi indicada pelo acadêmico Pedro Calmon para compor a referida coleção publicada na Argentina.

Vimos também que esses pontos se intercambiam para reforçar o reconhecimento da cientificidade da obra vianniana, não apenas no Brasil e entre os acadêmicos da $A B L$, mas entre escritores argentinos. O fato de Oliveira Vianna enviar um exemplar dessa tradução com dedicatória para a Biblioteca da $\mathrm{ABL}$ - antes mesmo de tomar posse na Academia -, além de seguir o habitus acadêmico também é uma forma de agradecer a indicação de sua obra para a coleção argentina e, ao mesmo tempo, demonstrar seu respeito à Instituição. A oferta da produção literária desse intelectual para a biblioteca da Academia também contribui com outra questão importante: a tese de que Oliveira Vianna compartilhou das formalidades inerentes aos membros da Casa de Machado de Assis, fazendo-se, assim, pertencente a essa "sociedade de indivíduos".

Avaliamos, também, que o intercâmbio entre Oliveira Vianna e a intelectualidade argentina não se deu apenas pela tradução dessa obra. Tal aproximação deu-se por outros caminhos, entre os quais, cartas e homenagens póstumas dirigidas a intelectuais argentinos, os quais se tornavam públicos por meio das sessões acadêmicas realizadas na Casa de Machado de Assis. A inserção de fragmentos de cartas nas obras e o agradecimento por meio de missivas demonstram que esse sujeito não se via isolado de outros intelectuais quando da elaboração de suas produções literárias. Ao contrário: esse intelectual sentia-se inserido em uma "sociedade de indivíduos"; em outras palavras, a pessoa singular se via em face da coletividade e se reconhecia nela.

Nessa "sociedade de indivíduos" formada em torno da ABL - na qual Oliveira Vianna foi exemplo para traçar o intercâmbio cultural entre escritores brasileiros e argentinos -, é 
possível perceber que a inter-relação entre esse grupo deu-se na elaboração de dois conjuntos literários: "Coleção de autores brasileños" e a "Biblioteca Brasileira de Autores Argentinos". O modelo seguido pelos dois grupos era a produção de obras literárias de cunho histórico e sociológico, mas isso não quer dizer que também não encontremos traduções de textos poéticos e de discursos políticos. De qualquer modo, a maior parte dos textos pertencentes a essas coleções tinha o caráter de tornar inteligível o processo histórico da formação de cada nação.

Assim, a discussão deste artigo pretende contribuir para o entendimento da utilidade de nos apropriarmos de coleções literárias para o mapeamento do campo intelectual e da "sociedade de indivíduos" que interagem em determinado contexto; em nosso caso, procurar, por meio do estudo dessas coleções, demonstrar como se estabeleceu a tentativa de intercâmbio cultural entre escritores brasileiros e argentinos nas décadas de 1930 e 1940

\section{BIBLIOGRAFIA}

ABL. Panorama da Literatura Estrangeira Contemporânea. Rio de Janeiro: Debeschi, 1943.

ABL. Revista da Academia Brasileira de Letras. v. 54. Rio de Janeiro: Debeschi, 1937.

BLOCH, Marc. Apologia da História ou o ofício do historiador. Rio de Janeiro: Zahar, 2002.

ABL. Estatuto. Rio de janeiro: Debeschi, 1940.

BRASIL, Decreto n. 24.394, de 13 de junho de 1934. Promulga o Convênio de Intercâmbio intelectual entre o Brasil e a argentina. Disponível em: http://www2.camara.leg.br/legin/fed/decret/19301939/decreto-24394-13-junho-1934-558093-publicacaooriginal-78991-pe.html Acessado em: 25/06/2017.

BRESCIANI, Maria Stella Martins. O charme da ciência e a sedução da objetividade: Oliveira Vianna entre intérpretes do Brasil. 2a edição. São Paulo: Editora UNESP, 2007.

EL FAR, Alessandra. A encenação da imortalidade: uma análise da Academia Brasileira de Letras nos anos da República (1897-1924). Rio de Janeiro: Editora FGV, 2000.

ELIAS, Norbert. A sociedade dos indivíduos. Rio de Janeiro: Zahar, 1994.

SORÁ, Gustavo. Livros de autores brasileiros na Argentina: uma força de alteridade negada. In. MARTINS, Maria Helena (org.) Fronteiras Culturais. Brasil-Uruguai-Argentina. São Paulo: Ateliê Editora, 2002. p. 170-209

RIVAROLA, Rodolfo. Prefácio. In. Evolución del pueblo brasileño. Buenos Aires: Ministério de Justiça e Instrução Pública, 1937. p. 9-16

RODRIGUES, João Paulo Coelho de Souza. A dança das cadeiras - Literatura e política na Academia Brasileira de Letras (1896-1913). Campinas, SP: Editora da Unicamp, 2001.

TORRES, Vasconcelos. Oliveira Vianna: sua vida e sua obra nos estudos brasileiros de sociologia. Rio de Janeiro: Livraria Freitas Bastos S.A., 1956. 
VENANCIO, Giselle Martins. Oliveira Vianna entre o espelho e a máscara. Belo Horizonte: Autêntica Editora, 2015.

VIANNA, Oliveira. Evolução do povo brasileiro. São Paulo: Monteiro Lobado CO, 1923. . Evolução do povo brasileiro. 2a edição. São Paulo: Companhia Editora nacional, 1933. . Evolução do povo brasileiro. 3a edição. São Paulo: Companhia Editora nacional, 1938. . Evolução do povo brasileiro. 4a Edição. São Paulo: Livraria José Olympio Editora, 1956. . Populações Meridionais do Brasil. São Paulo: Companhia Editora Nacional, 1938. 